\title{
Curricular evaluation of "SHOKUIKU program" as a postgraduate minor course of food and nutrition education using a text-mining procedure
}

\author{
Tomoko Ishikawa', Yoko Sato ${ }^{2}$, Kyoko Kurimoto', Yasuko Sone ${ }^{3}$, Rie Akamatsu ${ }^{2}$ and Yoko Fujiwara ${ }^{1,2^{*}}$
}

\begin{abstract}
Background: "SHOKUIKU", food and nutrition education, is a national promotion to enable people to acquire an adequate knowledge of SHOKU (which include food, nutrition, dietary habits, etc.) in Japanese society and to allow people to make appropriate SHOKU choices in Japan. In order to educate SHOKUIKU experts who can promote evidence-based SHOKUIKU with advanced professional knowledge and skills, an original "SHOKUIKU program" was established. To evaluate this program, a short answer questionnaire was given to students. Results were objectively analyzed by text mining procedures.
\end{abstract}

Methods: Five hundred forty four comment papers submitted by a total of 52 consenting students after each lecture in the 12 omnibus-style lectures were examined as cross-sectional data. A total of 2507 sentences were decomposed into words, and word classes of morpheme in Japanese were properly specified. Subsequently, on the basis of a constructed keyword data base, 123 morphemes with high frequency were investigated with co-occurrence network analysis. Furthermore, multivariate network analyses according to the student's major were performed.

Results: Students majoring in food and nutritional sciences recognized that evidence-based SHOKUIKU is "difficult" but "necessary" to "convey" reliable information at "actual" SHOKUIKU sites. On the other hand, students studying other majors not only got an "interesting" opportunity to "learn" "nutrition" and "eating habits" but also thought about their own SHOKUIKU promotion in relation to their major.

Conclusions: These results suggest that the students of the Food Course assumed that they would practice the evidence-based SHOKUIKU themselves, while the students of other courses learned new knowledge more passively. The results also confirmed that students comprehensively grasped the 12 omnibus-style lectures and understood the significance of evidence-based SHOKUIKU regardless of their major. Our original educational program could be valuable for postgraduate students to promote SHOKUIKU.

Keywords: Diet, food, and nutrition, Training programs, Program appropriateness, Text mining, Qualitative evaluation

\footnotetext{
* Correspondence: fujiwara.yoko@ocha.ac.jp

${ }^{1}$ Institute for Human Life Innovation, Ochanomizu University, 2-1-1 Otsuka,

Bunkyo-ku, Tokyo 112-8610, Japan

${ }^{2}$ Natural Science Division, Faculty of Core Research, Ochanomizu University,

Tokyo 112-8610, Japan

Full list of author information is available at the end of the article
}

(c) The Author(s). 2018 Open Access This article is distributed under the terms of the Creative Commons Attribution 4.0 International License (http://creativecommons.org/licenses/by/4.0/), which permits unrestricted use, distribution, and reproduction in any medium, provided you give appropriate credit to the original author(s) and the source, provide a link to the Creative Commons license, and indicate if changes were made. The Creative Commons Public Domain Dedication waiver (http://creativecommons.org/publicdomain/zero/1.0/) applies to the data made available in this article, unless otherwise stated. 


\section{Background}

\section{Social background}

The extension of a healthy life expectancy in Japan has attracted global attention, as Japan has become a super aged society ahead of the world. However, excessive dietary intake and also nutritional deficiency attributed to a poor appreciation for diet and nutrition remains, even in developed countries [1,2]. Japan is no exception, and it is imperative to reduce nutritional disorders including both hypernutrition and malnutrition [3].

In 2013, WASHOKU (WA-SHOKU), which means traditional Japanese (WA) food (SHOKU) culture, was chosen for the Intangible Cultural Heritage of the United Nations Educational, Scientific and Cultural Organization (UNESCO) as a social practice based on a set of skills, knowledge, practice, and traditions [4]. As it is known that traditional Japanese food is one of the most healthful and well-balanced diets in the world, the health of people in Japan has benefited from this desirable eating custom. During the 1960s, with international trade liberalization, the traditional Japanese diet based on rice, fish, soybeans, etc. was extended with the addition of meat and dairy products [5]. An intervention study reproducing Japanese diets according to different time periods showed that the Japanese diet in 1975 was the best in nutritional function [6]. However, the original balance of ingredients has gradually collapsed, and lifestyle diseases such as arteriosclerosis, diabetes, and cancer have increased significantly in Japan [7]. To maintain health, it is important to understand the characteristics of the traditional Japanese diet with its significant health benefits, and to practice it.

\section{Importance of SHOKUIKU}

To address such issues and to cultivate desirable food customs in the future, the Japanese Basic Law on SHOKUIKU (SHOKU-IKU), which means food (SHOKU) education (IKU), was established in 2005 [8, 9]. The Basic Law defines SHOKUIKU as acquisition of knowledge about food as well as the ability to make appropriate food choices. To fulfill the principles of the Basic Law, a SHOKUIKU Promotion Plan is formulated every five years in which the key challenges and goals in popularizing the ideas of diet, nutrition, and food culture are established [10]. Though the term SHOKUIKU may sound new, the first appearance of SHOKUIKU dates back to the Meiji era (1868-1912). S. Ishizuka, a military pharmacist, mentioned that physical, intellectual, and moral education is in the end all about SHOKUIKU [11, 12]. His views were incorporated into the Basic Law, in which the Japanese government stated that "SHOKUIKU makes the foundation for living, and is positioned as the base of intellectual (Chiiku), moral (Tokuiku) and physical (Taiiku) education". In this manner, SHOKUIKU lays the basic foundations for the practice and improvement of life skills. SHOKUIKU includes comprehensive educational activities not only for individuals but also for communities, whereas nutrition education and clinical nutrition instruction are for individuals.

Since the enforcement of the Basic Law, several public and private activities to promote SHOKUIKU have been carried out in various situations, such as at schools, in the local community, and at home. As a result of this wide dissemination of SHOKUIKU, people have begun to show great concern about healthful diets, food safety and conservation of global environments. However, the flood of information, especially uncertain information without scientific evidence, sometimes confuses people. In response to this world wide problem, the American Dietetic Association released a statement urging consumers to consider a meal as a whole, instead of judging specific foods as good or bad [13]. One of the causes of this confusion in Japan is SHOKUIKU professionals' lack of expertise in nutrition, food culture, production, security, humanities and habits, and practical skills. In Japan, though the training of registered dietitians is carried out in authorized facilities, the training curriculum of SHOKUIKU experts has not been established on similar evidence based foundations. SHOKUIKU must be based on trustworthy evidence from high quality academic research.

\section{SHOKUIKU curriculum overview}

In order to educate SHOKUIKU experts who can promote evidence-based and occasion-suited SHOKUIKU with advanced knowledge based on transdisciplinary viewpoints and practical skills, an original minor course "SHOKUIKU program" was established in 2011 in the Ochanomizu University graduate school, which is a women's university belonging to the national university corporation $[14,15]$. The SHOKUIKU program is composed of five integrated subjects, and the core subject is "Evidence of Dietary Education" which is a multilateral subject consisting of lectures in omnibus form on the importance of evidence in SHOKUIKU, and how to construct and comprehend it.

The most distinctive feature of this program is its integration of arts and sciences. Ochanomizu University graduate school has five major courses (Comparative Studies of Societies and Cultures, Human Developmental Sciences, Gender and Social Sciences, Life Sciences, Advanced Sciences). Any graduate student can register in this program regardless of her major. The purpose of the SHOKUIKU program as a postgraduate curriculum is to expand the curriculum utilizing the character of each academic discipline, and to educate multi skilled and resourceful experts of SHOKU and SHOKUIKU. This feature makes lecture preparation difficult, but it is important to make effective lectures. 
There are few universities with curricula specializing in SHOKUIKU education are available. In Italy, undergraduate and graduate programs in Gastronomic sciences in the University of Gastronomic Sciences implemented complementary education in both sciences and humanities, sensory training, and hands-on learning [16]. A practical "SHOKUIKU" program in Japan has been established as an undergraduate minor program in Ehime University to improve students' own eating behaviors, but not to educate leaders of SHOKUIKU [17]. However, a multidisciplinary and comprehensive academic curriculum in a postgraduate course to educate SHOKUIKU experts is absent except at Ochanomizu University.

\section{Evaluation of the program}

Newly introduced education programs are generally required to objectively validate the educational implications, as has been the case with problem-based learning (PBL) $[18,19]$. The SHOKUIKU program is a newly established educational program integrating the arts and sciences, and an evaluation of this program is needed. The aims of this study are to verify whether students of the core subject, "Evidence of Dietary Education" reacted differently to the lectures based on their major, and to see if they were able to gain an integrated understanding of the 12 omnibus-style lectures. To analyze the data obtained, we selected the text-mining method. Text-mining is an exploratory analysis procedure to extract useful information automatically and objectively from huge unstructured textual data. The text-mining tools are being effectively utilized in the interpretation of huge amounts of data in various fields, such as biology, informatics, and education [20, 21]. For the purpose of evaluating the benefits of the lectures, text-mining analyses are also used to interpret comments obtained from students objectively [22, 23]. This study attempts to analyze the answer sentences in a short answer questionnaire obtained from the students registering the core subject "Evidence of Dietary Education".

\section{Methods}

\section{Subjects}

Sixty graduate students registered in the core omnibus subject of the SHOKUIKU program, "Evidence of Dietary Education", in 2012 and 2013. From the eligible participants, 52 students consented to this research. The consent rate was $86.7 \%$. Table 1 shows the majors of consenting students. Subjects were divided into the food and nutritional sciences course (Food Course) and otherwise, according to major. The mean attendance rate of the consenting students was $90.5 \%$ overall, and there was no difference between the Food Course and otherwise.
Table 1 Number of students in major courses analyzed in this study

\begin{tabular}{lll}
\hline Major course & $\begin{array}{l}\text { Number of } \\
\text { students }\end{array}$ & $\begin{array}{l}\text { Groups for } \\
\text { comparative analysis }\end{array}$ \\
\hline Food and nutritional science & 29 & $\begin{array}{l}\text { Food Course } \\
\text { Food and nutritional science } \\
\text { (Doctoral program) }\end{array}$ \\
$\begin{array}{l}\text { Psychology } \\
\text { Child Studies }\end{array}$ & 3 & $\begin{array}{l}\text { Other Courses } \\
\text { Japanese Language and }\end{array}$ \\
$\begin{array}{l}\text { Literature } \\
\text { Comparative Studies of Societies } \\
\text { and Cultures (Doctoral program) }\end{array}$ & 1 & 18 \\
Human Environmental Sciences & 1 & \\
Biological Sciences & 4 & \\
Physics & 6 & \\
Chemistry and Biochemistry & 1 &
\end{tabular}

Almost all students of the Food Course were graduates of the Department of Nutrition and Food Science, which trains registered dietitians. The students of other courses had not received specialized education about food and nutrition since junior high school or high school. However, the analyses indicated that all students were able to understand the point of the lesson, but there was a difference in recognition of the SHOKUIKU promotion that they will carry out in the future.

\section{Data collection}

The theme of each individual lecture is categorized in Table 2. After each lesson, students were required to submit a comment paper, which was an A5 sized short-answer questionnaire with columns for the date, theme of the lesson, register number, full name, major, grade, and a free space $(114 \mathrm{~mm} \times 130 \mathrm{~mm})$ for anything they learned, thought, and felt about the lesson. Comment papers were collected at a total of 24 lessons in

Table 2 Categorization of subject contents

\begin{tabular}{ll}
\hline Lesson & Theme \\
\hline 1 & Introduction \\
2 & Cookery science \\
3 & Japanese food culture \\
4 & Food chemistry \\
5 & Functional food \\
6 & Nutritional chemistry \\
7 & Biological function \\
8 & Nutritional epidemiology \\
9 & Promotion of SHOKUIKU \\
10 & SHOKUIKU for handicapped \\
11 & Study for SHOKUIKU \\
12 & SHOKUIKU in a company \\
\hline
\end{tabular}


2012 and 2013, and only the papers obtained from consenting students were used. In order to secure anonymity, all textual comments were digitized with the theme of the lesson and the major of the individual. The digitizing data were checked by multiple researchers.

\section{Analytical procedure}

Usually in qualitative analyses, content or thematic analysis is conducted. However, the aim of this study is to analyze the co-occurrence of the morphemes (the smallest meaningful unit of language) extracted and categorized from the data, and objectively express their relationships with the majors of the students, and the lecture themes, respectively. For this, we chose the text mining method to attempt to show the combinations of morphemes that were reported by the respondents. The quantitative text mining analyses $[24,25]$ were performed using a free software, $\mathrm{KH}$ Coder [26, 27], which can analyze Japanese, English, German, Italian, Portuguese and Spanish text. In this study, ChaSen [28], a Japanese morphological analysis tool retained by Matsumoto Laboratory at Nara Institute of Science and Technology was used as the backend program. KH Coder provides a morpheme frequency table and visualizes co-occurrence networks among morphemes using the R [29], which is an integrated suite of software functions for statistical computation and graphical display provided by GNU projects [30].

The data consisting of 546 comments were served for sequential quantitative analysis. All data were automatically decomposed into morphemes, then extracted morphemes were classified into parts of speech, the appearance frequencies were calculated, and the relationships between each morpheme were analyzed. Next, the morphemes that were categorized into compound or unknown terms were checked and confirmed with the original comment sentence retroactively in order to pick up specific compound terms and technical terminology concerning this program such as cookery science and registered dietitian. Finally, the interrelationships among morphemes were visualized as the co-occurrence networks.

All original sentences were analyzed in Japanese, and the final results were translated into English for this report.

\section{Results}

\section{Morpheme analysis}

Using the automatic morpheme analysis, 4044 terms were extracted from all comments, classified into 13 parts of speech, the appearance frequencies were calculated, and the relationships between each morpheme were analyzed (Table 3 ). The common terms reported by the participants were "research (245)", "SHOKUIKU (237)", and "evidence (219)".

\section{Co-occurrence network analysis}

One hundred twenty one terms with appearance frequencies between 30 and 300 were served for sequential co-occurrence network analysis. The intensity of co-occurrence relationships among morphemes is indicated in Fig. 1. Including slightly weak relationships, focused morphemes were automatically classified based on centricity in the network. Unlike multidimensional linear measures (MDS), the relationships are significant when two morphemes are joined together in this study. However, if two morphemes are just placed near each other but not bound together, there is not a strong relationship between them. In the figures, a morpheme with higher appearance frequency is indicated as a bigger circle, and automatically classified group is separated by color. Two morphemes that have a strong relationship between them are joined with a bold line.

In Fig. 1, three particularly interesting groups in the morpheme network were revealed. In the first group, the central morpheme was "evidence", linked to "information-necessary-knowledge", "accurate", "learn", and "scientific" (indicated by moss green in Fig. 1). Students acquired the importance of applying information based on scientific evidence to SHOKUIKU. For this purpose, appropriate knowledge is indispensable. The next group (indicated by yellow in Fig. 1) formed a network with "SHOKUIKU", "SHOKU", "know", "consider", and "research". Students knew about various fields of research on food or SHOKUIKU, and considered the relationships between their own research in their major course and SHOKUIKU. In another group (indicated by light purple in Fig. 1), the central morpheme was "interest", linked to "topic-listen-today-lesson" and "significant". Students regarded each lesson as a significant and valuable opportunity, and listened with great interest.

\section{Comparisons between major courses}

Co-occurrence network analysis methods were used to compare the perceptions of the students in the Food Course with those from other courses. The results are shown in Fig. 2. The students of the Food Course recognized that evidence-based SHOKUIKU was "necessary", "essential", and of "importance" at "actual" SHOKUIKU sites, and perceived and referred to it as being "difficult" to "convey" the right information exactly. The students of other courses tended to view the lessons more passively. For example, they mentioned a "first" and "interesting" opportunity to "learn" unknown fields (e.g. "nutrition", "eating habits") that "differ" from their major. However, they also referred to situations to improve their own "eating habits" or to act on SHOKUIKU from the viewpoints of their fields.

\section{Integrated understanding of lesson content}

The integrated understanding of the content of each lesson was then examined in detail (Fig. 3). A total of 126 


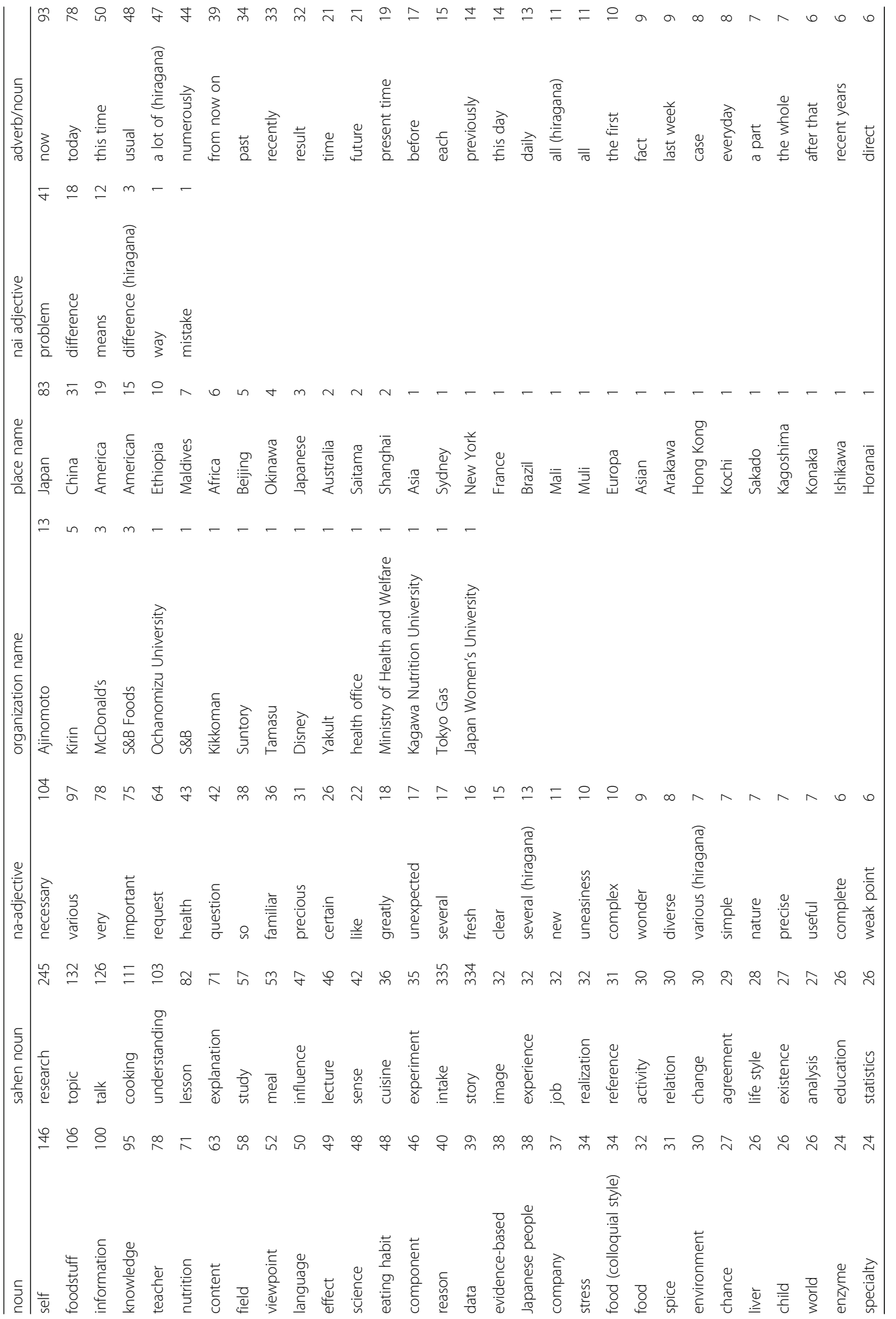




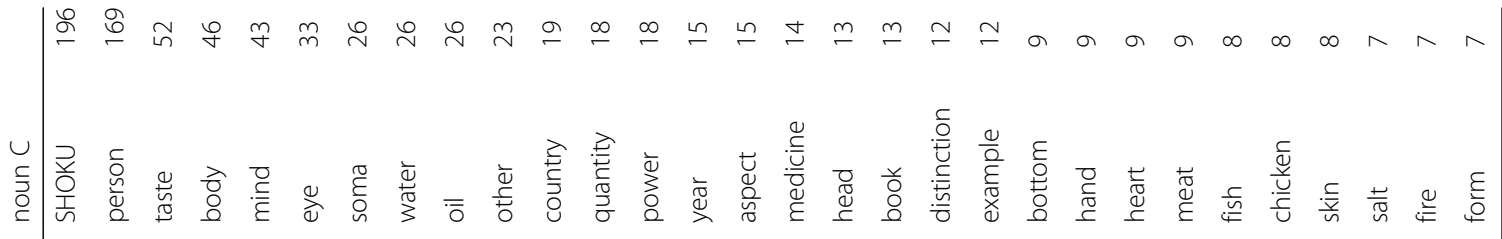

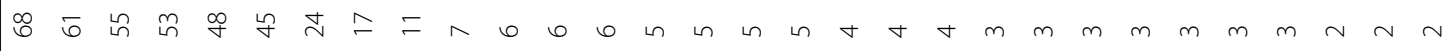

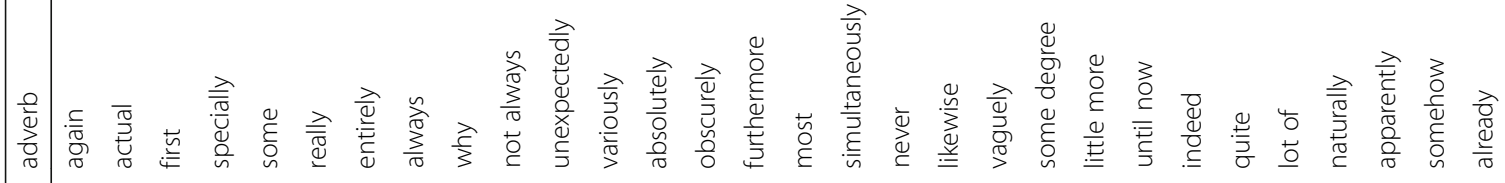

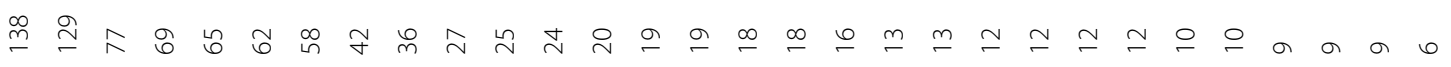

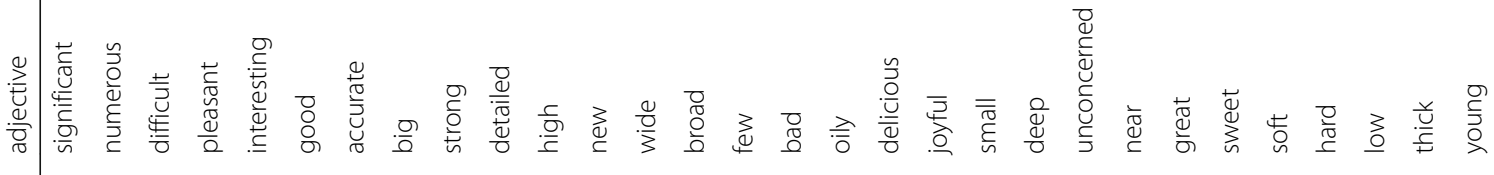

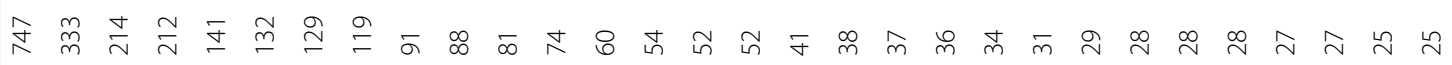

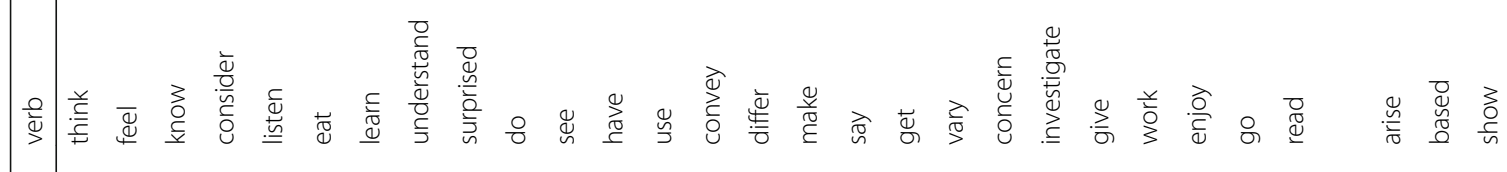
$\infty \quad m a$ o

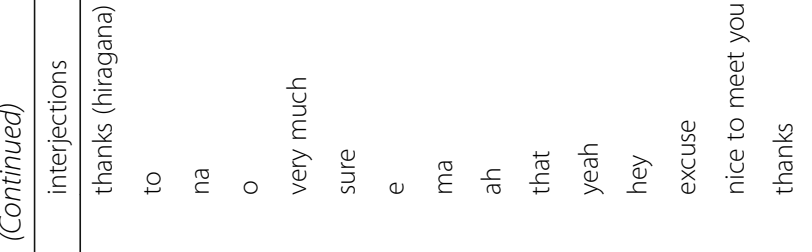

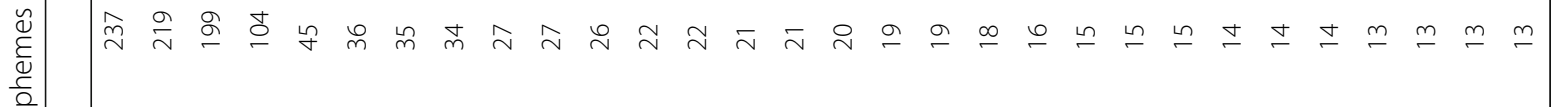

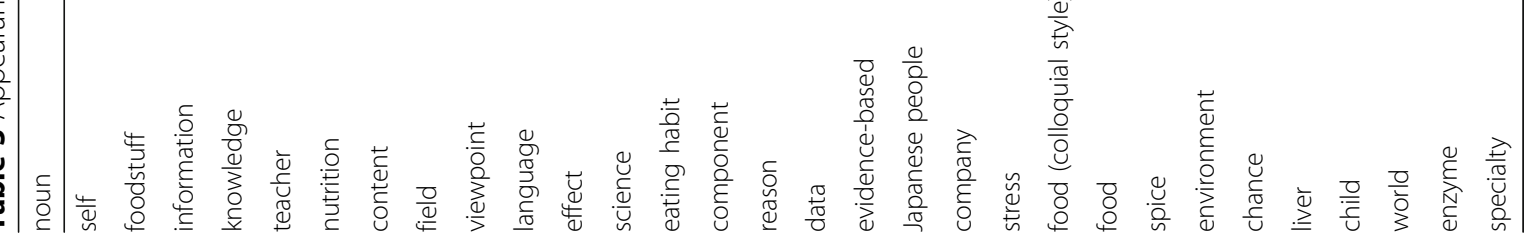




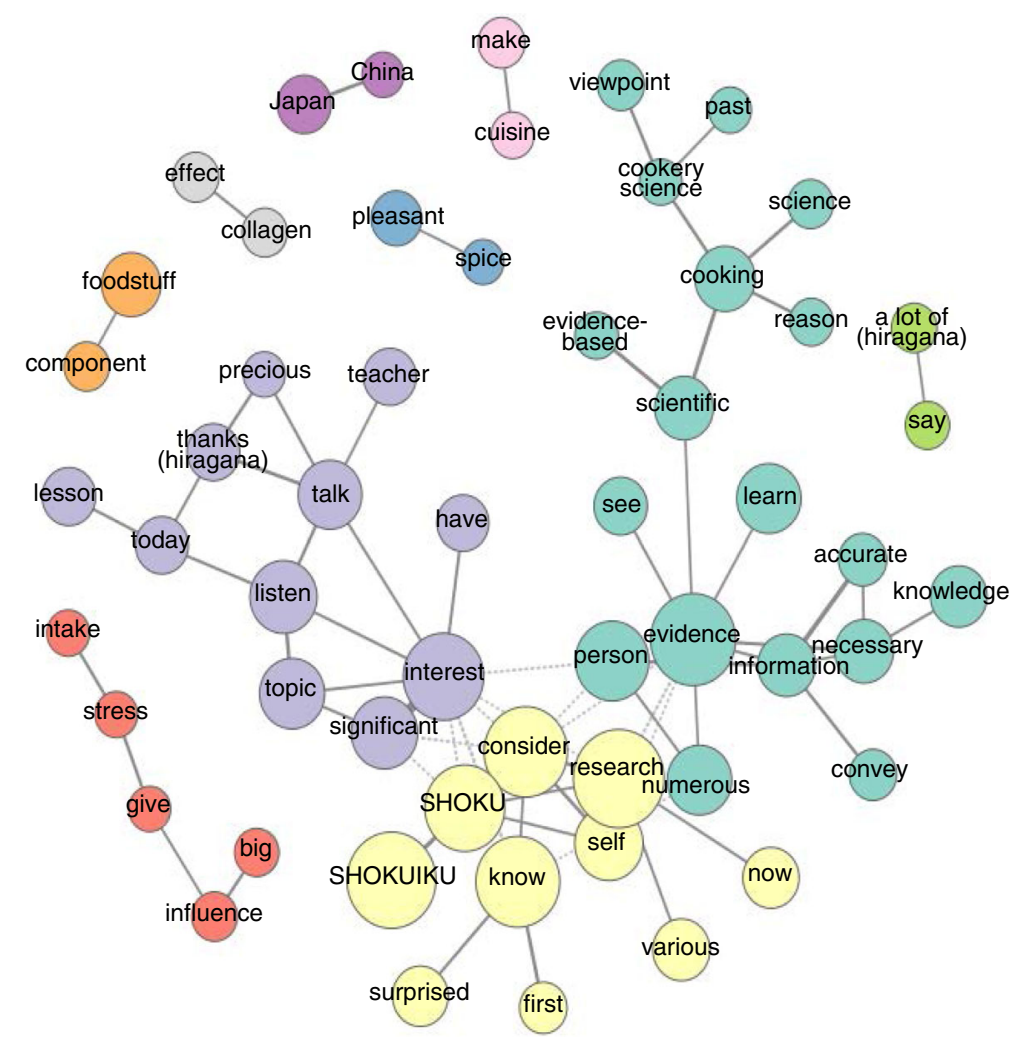

Fig. 1 Co-occurrence network among extracted morphemes

terms in descending order of the occurrence frequency were used for this analysis for the Food Course and the other courses, respectively.

For Food Course students (Fig. 3a), many morphemes showed that students understood the important points of each lesson, namely "evidence", "SHOKU", "SHOKUIKU", "interest" and "person". Moreover, the verb "think", which implies a simple impression, was associated with few comments. Strong co-occurrence relationships between a term and the theme of each lesson were found as follows; "science" correlated to the theme "Cookery science"; "evidence" or "person" correlated to the theme "Nutritional chemistry"; and "SHOKU" correlated to the theme "Biological function". On the other hand, for students in other courses (Fig. 3b), many of their reports concluded with a verb, such as "think", "know", or "feel". However, the theme of each lesson accurately co-occurred with terms indicating the purpose or point of the lesson. For example, the theme "Nutritional chemistry" correlated to "evidence" and "knowledge", the theme "Nutritional epidemiology" correlated to "necessary" and "information", and the theme "Cookery science" correlated to "scientific" and "reason". The themes strongly co-occurring with "SHOKU" or "SHOKUIKU" were "Introduction", "Food chemistry", and "Biological function".

\section{Discussion}

A core subject, "Evidence of Dietary Education", of our original postgraduate curriculum training SHOKUIKU experts was evaluated using a text-mining method to analyze short answer questionnaire sentences obtained from students. As a result of the co-occurrence network analysis, we found that the students had different impressions of the lessons according to their major, and that students were able to understand the 12 omnibus-style lectures comprehensively.

In the comparison between the Food Course and the other courses, the difference between the two groups was revealed. The students of the Food Course recognized the importance of accurately communicating correct information, and realized its difficulty and necessity, assuming that they would perform this action themselves at actual SHOKUIKU sites. The students of other courses tended to view the lessons more passively. They were also able to grasp the contents of each lesson clearly, though perhaps it was the initial opportunity to learn about "SHOKU" for most of them. We consider that it is necessary to develop an environment for SHOKU education in junior high school and high school as subjects within home economics or other disciplines and in university as a subject of liberal arts. 


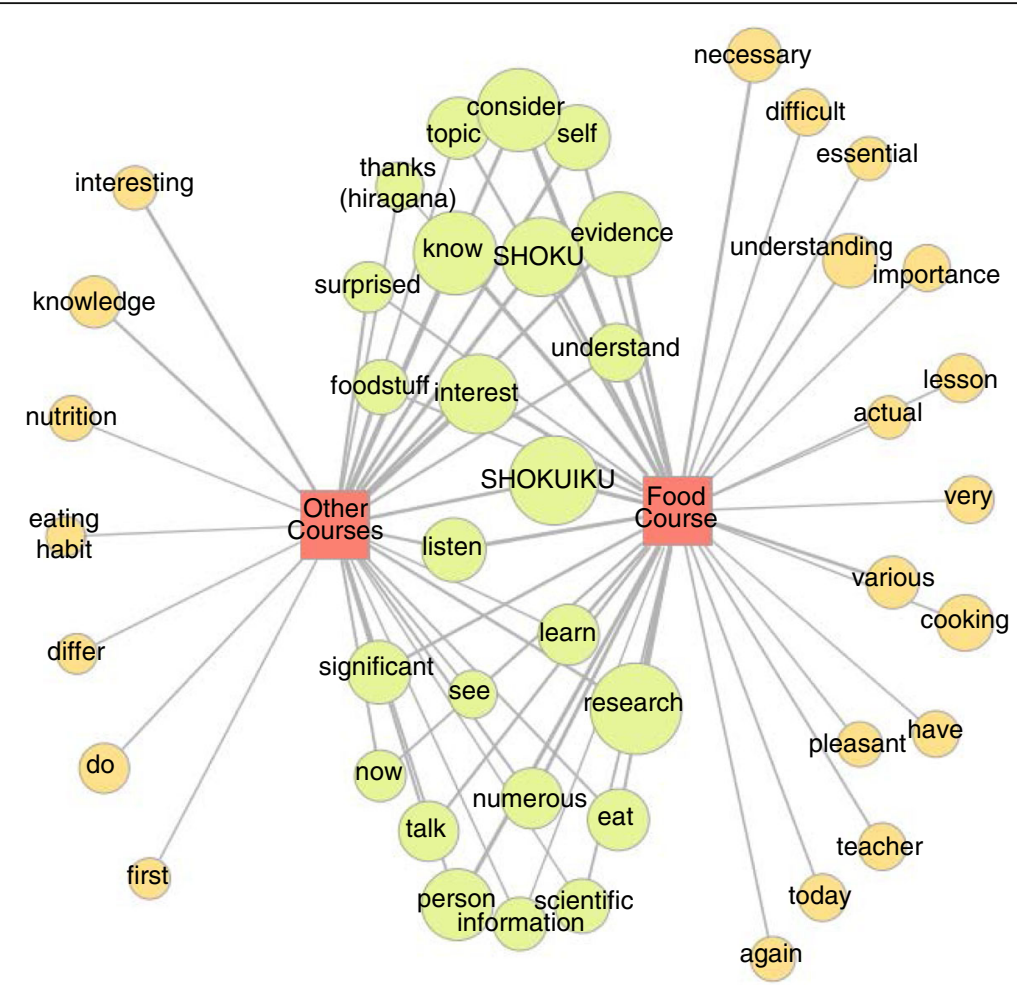

Fig. 2 Co-occurrence relationship between major and morpheme

From the co-occurrence network analysis with each lesson theme, it became clear that students of both groups comprehensively understood the lecture contents in omnibus form. These results show that regardless of student characteristic, the 12 lecture contents are linked together to cultivate a multifaceted perspective and integrated thinking on SHOKU and SHOKUIKU.

Recently, several competency-based evaluations of education programs have been performed. The development of the competency model in education programs is considered desirable in order to improve the efficiency of the program [31]. In this case, it is possible to evaluate the programs quantitatively and to ask for the achievement of competencies in a pre-code type questionnaire. The desired competencies themselves can then become the evaluation criteria. Using this method, an evaluation survey has been performed for a statewide public health leadership training program [32], and for a peer leader training program in diabetes $[33,34]$. The pre-code type questionnaire provides a precise quantitative analysis, but answers are limited by question composition and choices. On the contrary, the short answer questionnaire is useful to penetrate into the subject's motives. The objective analysis can be performed by text-mining methodology. In the present study, using a quantitative text mining software, $\mathrm{KH}$ Coder, multivariate analyses were performed to summarize the data while excluding the intention of researchers, and then co-occurrence networks were visualized to interpret students' comments.

\section{Limitations}

There are limitations in this study. First is the reliability of automatic analysis by the text-mining software. $\mathrm{KH}$ Coder, though it is used worldwide, cannot cover all the technical terms and characteristic compound words by automatic morpheme extraction. To avoid overlooking any morphemes, the original sentence of every extracted morpheme was checked using the concordance function of $\mathrm{KH}$ Coder in this study. The second is that the study used cross-sectional textual data obtained from students, so comparison between before and after the lessons was impossible.

\section{Conclusions}

In this study, evaluation of the original minor course for SHOKUIKU in Ochanomizu University graduate school was performed by text mining to analyze the results of short answer questionnaires obtained from students. It was shown that all students comprehensively understood the 12 lecture contents, and achieved beneficial outcomes appropriate to their major as follows. The students of the Food Course recognized the importance of evidence-based 


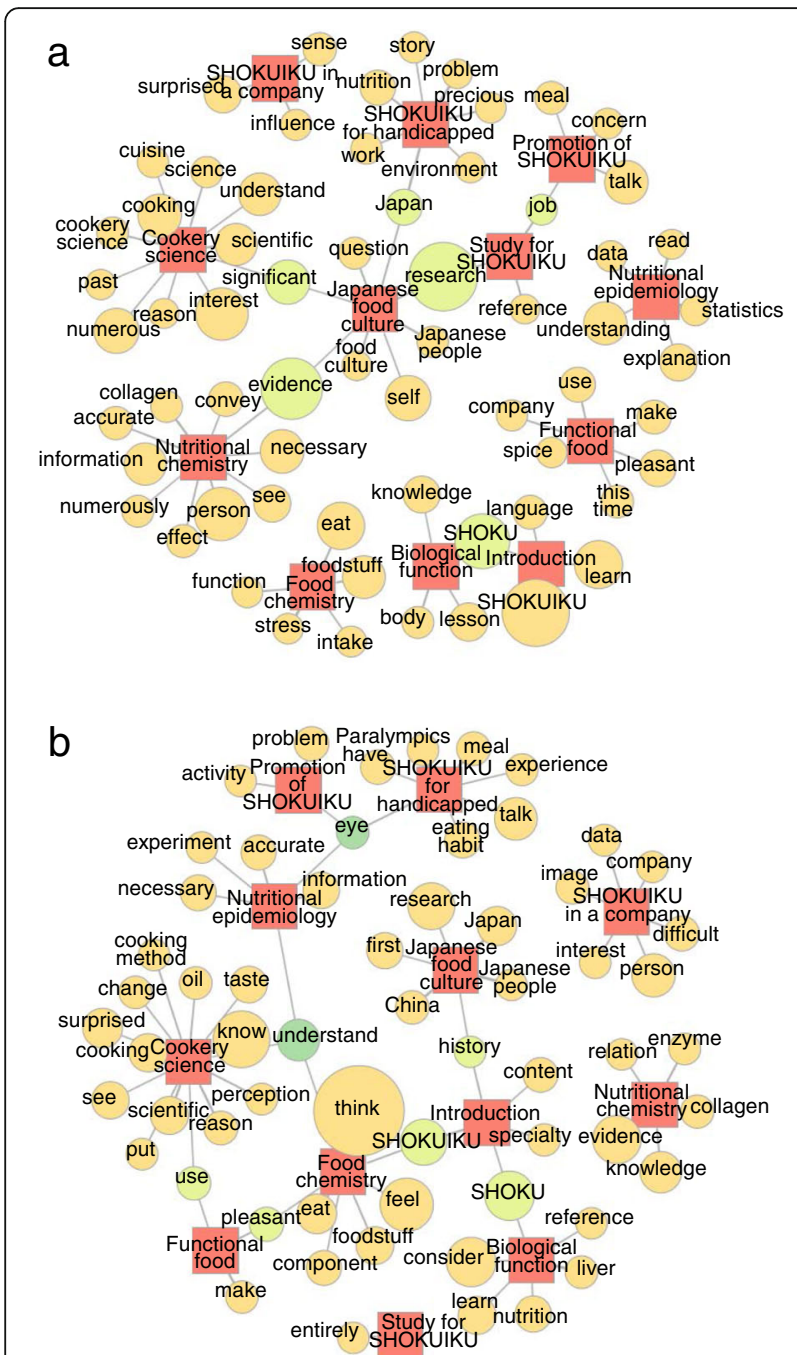

Fig. 3 Co-occurrence relationship between theme of lesson and morpheme. a Food Course. $\mathbf{b}$ Other Courses

SHOKUIKU, and its difficulty. The students of other courses got an opportunity for the first time to learn nutrition, eating habits, and evidence-based SHOKUIKU. The core subject "Evidence of Dietary Education" could be a valuable subject for postgraduate students to take to improve their own awareness and promote SHOKUIKU.

\section{Abbreviations}

MDS: Multidimensional linear measure; SHOKU: Food, nutrition and dietary habits, etc. in Japanese; SHOKUIKU: Food and nutrition education in Japanese; UNESCO: The United Nations Educational, Scientific and Cultural Organization; WASHOKU: Japanese traditional food and cultures

\section{Acknowledgements}

We would like to thank Ms. Gillian Read and Ms. Yuka Moriya for correcting grammatical errors and other problems with the language of the manuscript.

\section{Funding}

The SHOKUIKU project and this study have been funded by a grant from the Ministry of Education, Culture, Sports, Science and Technology (Apr. 2010-Mar. 2017).

\section{Availability of data and materials}

We have obtained consent for the use of analyzed results. The original answers and the raw data will not be publically available.

The text-mining software "KH Coder" used in this study is available from http://khc.sourceforge.net/en/.

\section{Authors' contributions}

TI conceived the study, participated in its design and coordination performed the text-mining analysis, and drafted the manuscript. YSa performed the translation of Japanese morphemes into English and helped to draft the manuscript. KK contributed to collect consent forms and data, performed digitalization of textual comments as cross-sectional data, and helped to draft the manuscript. YSo participated in its design and contributed to collect data. RA participated in its design and coordination and supervised the analysis, and helped to draft the manuscript. YF conceived the study, participated in its design and coordination, and helped to draft the manuscript. All authors have read and approved the final version of the manuscript.

\section{Authors' information}

Tl; Ph. D, project associate professor, in charge of "SHOKUIKU program". fields: nutrition science, molecular anatomy, medical education, SHOKUIKU. YSa; Ph. D, assistant professor, registered dietitian, Ochanomizu University SHOKUIKU senior expert. fields: cookery science, SHOKUIKU. KK; Ph. D, academic assistant. fields: social sciences. YSo; Ph. D, lecturer. fields: nutrition science, SHOKUIKU. RA; DrPH., professor, registered dietitian. fields: food and nutrition education, SHOKUIKU. YF; Ph. D, professor, project leader of the grant from the Ministry of Education, Culture, Sports, Science and Technology. fields: nutrition science, molecular nutrition, home economic education, SHOKUIKU.

Ethics approval and consent to participate

Ethical approval was granted by the Ethics Review Committee of Ochamonizu University (reference number 25-9). We have obtained written consent from students whose comments were analyzed in this study.

\section{Consent for publication}

Not applicable.

\section{Competing interests}

All authors declare that they have no competing interests.

\section{Publisher's Note}

Springer Nature remains neutral with regard to jurisdictional claims in published maps and institutional affiliations.

\section{Author details}

${ }^{1}$ Institute for Human Life Innovation, Ochanomizu University, 2-1-1 Otsuka, Bunkyo-ku, Tokyo 112-8610, Japan. ${ }^{2}$ Natural Science Division, Faculty of Core Research, Ochanomizu University, Tokyo 112-8610, Japan. ${ }^{3}$ Faculty of Health \& Nutrition, Takasaki University of Health and Welfare, 37-1 Nakaorui-machi, Takasaki-shi, Gunma 370-0033, Japan.

Received: 2 August 2017 Accepted: 10 August 2018 Published online: 22 November 2018

\section{References}

1. Lin P, Fintelmann RE, Khalifa YM, Bailony MR, Jeng BH. Ocular surface disease secondary to vitamin A deficiency in the developed world: it still exists. Arch Ophthalmol. 2011;129(6):798-9. https://doi.org/10.1001/ archophthalmol.2011.126.

2. Duignan E, Kenna P, Watson R, Fitzsimon S, Brosnahan D. Ophthalmic manifestations of vitamin a and d deficiency in two autistic teenagers: case reports and a review of the literature. Case Rep Ophthalmol. 2015;6(1):24-9. https://doi.org/10.1159/000373921.

3. Nishi N. Monitoring Obesity Trends in Health Japan 21. J Nutr Sci Vitaminol (Tokyo). 2015;61(Suppl):S17-9. https://doi.org/10.3177/jnsv.61.S17.

4. UNESC. Washoku, traditional dietary cultures of the Japanese, notably for the celebration of New Year [http://www.unesco.org/archives/multimedia/ ?s=films_details\&pg=33\&id=3516] 2013; Accessed 2 Aug, 2018. 
5. Ministry of Agriculture, Forestry and Fisheries. The Food Balance Sheet for FY2016.1. Trend for Food Balance. [https://www.e-stat.go.jp/stat-search/filedownload?statInfld=000031672863\&fileKind=2] 2018; Accessed 2 Aug, 2018.

6. Yamamoto K, E S, Hatakeyama Y, Sakamoto Y, Honma T, Jibu Y, Kawakami Y, Tsuduki T. The Japanese diet from 1975 delays senescence and prolongs life span in SAMP8 mice. Nutrition. 2016;32(1):122-8. https://doi.org/10.1016/j. nut.2015.07.002

7. Ministry of Health, Labour and welfare. The Overview of Patient Survey for 2014. [https://www.mhlw.go.jp/toukei/saikin/hw/kanja/14/dl/kanja.pdf] 2015; Accessed 2 Aug, 2018.

8. Nakamura T. The integration of school nutrition program into health promotion and prevention of lifestyle-related diseases in Japan. Asia Pac J Clin Nutr 2008; 17 Suppl 1:349-351. PMID: 18296376

9. Cabinet Office. Shokuiku Kihon $\mathrm{Ho}^{-}$(Food Education Basic Law). Act No. 63 of 2005, Japan. [http://www.maff.go.jp/j/syokuiku/pdf/kihonho_27911.pdf] 2015; Accessed 2 Aug, 2018.

10. Ministry of Agriculture, Forestry and Fisheries. The Third Basic Program for Shokuiku Promotion. [http://warp.da.ndl.go.jp/info:ndljp/pid/9929094/www8. cao.go.jp/syokuiku/about/plan/pdf/3kihonkeikaku.pdfl] 2016; Accessed 2 Aug, 2018.

11. Ishizuka S. Chemical Theory of Diet for Longevity. Tokyo: Hakubunkan; 1896. https://doi.org/10.11501/836793, http://dl.ndl.go.jp/info:ndljp/pid/836793

12. Ishizuka S. Diet for health. Tokyo: Ishizuka food hospital editorial department: 1899. https://doi.org/10.11501/934855, http://dl.ndl.go.jp/info:ndljp/pid/934855

13. Freeland-Graves JH, Nitzke S. Position of the academy of nutrition and dietetics: total diet approach to healthy eating. J Acad Nutr Diet. 2013; 113(2):307-17. https://doi.org/10.1016/j.jand.2012.12.013.

14. Ishikawa T, Fujiwara Y. Training of specialist on nutrition education in graduate school. J Japanese Soc Shokuiku 2014; 8(2):105-110. CiNii: https:// ci.nii.ac.jp/naid/40020091532, NDL: http://iss.ndl.go.jp/books/R0000000041025517455-00

15. SHOKUIKU program. Ochanomizu University. [http://www.cf.ocha.ac.jp/ ochashoku/] 2011; Accessed 2 Aug, 2018.

16. University of Gastronomic Sciences. [http://www.unisg.it/en/] 2017; Accessed 2 Aug, 2018.

17. Kakihara T, Ueda H, Fujiwara M, Kobayashi N, Nakamura K, Saheki S: "SHOKUIKU" program of Ehime University. J Faculty Staff Development Higher Educ 2012; 10:81-87. http://iyokan.lib.ehime-u.ac.jp/dspace/handle/ iyokan/1595.

18. Tseng FY, Shieh JY, Kao TW, Wu CC, Chu TS, Chen YY. Developing and Evaluating Medical Humanities Problem-Based Learning Classes Facilitated by the Teaching Assistants Majored in the Liberal Arts: A Longitudinal Crossover Study. Medicine (United States) 2016, 95(6):e2765. https://doi.org/ 10.1097/MD.0000000000002765.

19. Niwa M, Saiki T, Fujisaki K, Suzuki Y, Evans P. The Effects of Problem-BasedLearning on the Academic Achievements of Medical Students in One Japanese Medical School, Over a Twenty-Year Period. Health Prof Educ. 2016;2(1):3-9. https://doi.org/10.1016/j.hpe.2016.01.003.

20. Fleuren WWM, Alkema W. Application of text mining in the biomedical domain. Methods. 2015;74:97-106. https:/doi.org/10.1016/j.ymeth.2015.01.015.

21. Zawacki-Richter O, Latchem C. Exploring four decades of research in Computers \& Education. Comput Educ. 2018;122:136-52. https://doi.org/10. 1016/j.compedu.2018.04.001.

22. Nakagawa K, Asakawa Y, Yamada K, Ushikubo M, Yoshida T, Yamaguchi H. Benefits of off-campus education for students in the health sciences: a textmining analysis. BMC Med Educ. 2012;12:84-90. https://doi.org/10.1186/ 1472-6920-12-84.

23. Oza KS, Naik PG. Prediction of Online Lectures Popularity: A Text Mining Approach. Procedia Comput Sci. 2016;92:468-74. https://doi.org/10.1016/j. procs.2016.07.369.

24. Hasegawa A, Takahashi M, Nemoto M, Ohba T, Yamada C, Matsui S, Fujino M, Satoh K. Lexical analysis suggests differences between subgroups in anxieties over radiation exposure in Fukushima. J Radiat Res 2018; 59(suppl_ 2):ii83-ii90. https://doi.org/10.1093/jrr/rry027.

25. Tang L, Bie B, Zhi D. Tweeting about measles during stages of an outbreak: A semantic network approach to the framing of an emerging infectious disease. Am J Infect Control. 2018; Available online 19 June 2018. https:// doi.org/10.1016/j.ajic.2018.05.019.

26. Higuchi K. Quantitative Analysis of Textual Data:Differentiation and Coordination of Two Approaches. Sociological Theory and Methods. 2004; 19(1):101-15.
27. The KH Coder Index Page. [http://khc.sourceforge.net/en/] 2001; Accessed 2 Aug, 2018.

28. ChaSen legacy Project. [http://sourceforge.jp/projects/chasen-legacy/] 2006; Accessed 2 Aug, 2018.

29. Li J, Shin SY, Lee HC. Text mining and visualization of papers reviews using R language. J Inf Commun Converg Eng. 2017;15(3):170-4. https://doi.org/ 10.6109/jicce.2017.15.3.170.

30. The R Official Site. [http://www.r-project.org/] 2017; Accessed 2 Aug, 2018.

31. Chambers DW, Gilmore CJ, Maillet JO, Mitchell BE. Another look at competency-based education in dietetics. J Am Diet Assoc. 1996;96(6):6147. https://doi.org/10.1016/S0002-8223(96)00172-1.

32. Hawley SR, St Romain T, Orr SA, Molgaard CA, Kabler BS. Competency-based impact of a statewide public health leadership training program. Health Promot Pract. 2011;12(2):202-8. https://doi.org/10.1177/1524839909349163.

33. Tang TS, Funnell MM, Gillard M, Nwankwo R, Heisler M. The development of a pilot training program for peer leaders in diabetes: process and content. Diabetes Educ. 2011;37(1):67-77. https://doi.org/10.1177/0145721710387308.

34. Tang TS, Sohal PS, Garg AK. Evaluating a diabetes self-management support peer leader training programme for the English- and Punjabi-speaking South-Asian community in Vancouver. Diabet Med 2013; 30(6):746-752. https://doi.org/10.1111/dme.12179.
Ready to submit your research? Choose BMC and benefit from:

- fast, convenient online submission

- thorough peer review by experienced researchers in your field

- rapid publication on acceptance

- support for research data, including large and complex data types

- gold Open Access which fosters wider collaboration and increased citations

- maximum visibility for your research: over $100 \mathrm{M}$ website views per year

At BMC, research is always in progress.

Learn more biomedcentral.com/submissions 